\title{
APLICAÇÃO DE ÓLEO FÚSEL NA ERRADICAÇÃO QUÍMICA DA CANA-DE-AÇÚCAR E SEU EFEITO NA CULTURA DO GIRASSOL EM SUCESSÃO ( ${ }^{(1)}$
}

\author{
CARLOS ALBERTO MATHIAS AZANIA $\left(2^{*}\right)$; ANDRÉA APARECIDA DE PADUA MATHIAS AZANIA $(2,3)$; \\ JOSÉ CARLOS ROLIM (2,3); ANA REGINA SCHIAVETTO (2,4); IGOR VANZELA PIZZO (2,5); \\ FABRÍCIO SIMONE ZERA $(2,6)$
}

\begin{abstract}
RESUMO
O óleo fúsel é o único resíduo da indústria sucroalcooleira que não é utilizado na agricultura; assim, foram iniciados trabalhos envolvendo seu uso na agricultura, evidenciando o potencial herbicida. O trabalho objetivou estudar a erradicação das soqueiras de cana-de-açúcar submetidas a diferentes concentrações de óleo fúsel, pulverizado e aplicado via solo, além da sucessão do girassol. O estudo foi realizado em Ribeirão Preto (SP), de 2006 a 2007, em delineamento inteiramente casualizado com três repetições. A primeira etapa constou de 22 tratamentos em esquema fatorial 7 × 3 constituído pelas concentrações do óleo fúsel $(6,5 ; 12 ; 25 ; 50 ; 75$ e $100 \%)$ e glifosato (2520 $\left.\mathrm{g} \mathrm{ha}^{-1}\right)$ e pelos volumes de calda $\left(250,350\right.$ e $\left.450 \mathrm{~L} \mathrm{ha}^{-1}\right)$ mais testemunha adicional; a segunda etapa foi constituída por 12 tratamentos $\left(0 ; 0,1 ; 0,5 ; 01 ; 05 ; 10 ; 25 ; 50 ; 75 ; 100 ; 125 ; 150 \mathrm{~m}^{-3} \mathrm{ha}^{-1}\right)$ e a terceira etapa por oito tratamentos $\left(05 ; 10 ; 25 ; 50 ; 75 ; 100 ; 125 ; 150 \mathrm{~m}^{-3} \mathrm{ha}^{-1}\right)$. O óleo fúsel aplicado via pulverização na cana-de-açúcar não erradicou as soqueiras, no entanto, a aplicação diretamente no solo foi eficiente na erradicação das soqueiras e não prejudicou o desenvolvimento de plantas de girassol em sucessão.
\end{abstract}

Palavras-chave: Saccharum spp., Helianthus annuus, resíduo agroindustrial, soqueiras.

\section{ABSTRACT \\ OIL FUSEL APPLICATION ON THE SUGARCANE CHEMICAL ERADICATION AND ITS EFFECT ON SUNFLOWER SEQUENTIAL CROP}

The fusel oil is the only residue of sugarcane industry that is not used in agriculture, thus the work has started involving use in agriculture, showing the herbicide potential. The study investigated the sugarcane ratoons eradication under different fusel oil concentrations, sprayed and applied under soil and the sunflower succession. The study was conducted in Ribeirão Preto region, State of São Paulo, Brazil, from 2006 to 2007, in a completely randomized design with 3 replications. The first stage consisted of 22 treatments arranged in a factorial arrangement $7 \times 3$ consists of the fusel oil concentrations $(6.5,12,25,50,75$ and $100 \%)$ and glyphosate $\left(2520 \mathrm{~g} \mathrm{ha}^{-1}\right)$ and the water volumes $\left(250,350\right.$, and $\left.450 \mathrm{~L} \mathrm{ha}^{-1}\right)$ with additional check; the second stage was composed of 12 treatments $(0,0.1$, $\left.0.5,01,05,10,25,50,75,100,125,150 \mathrm{~m}^{-3} \mathrm{ha}^{-1}\right)$ and the third stage of 8 treatments $\left(05,10,25,50,75,100,125,150 \mathrm{~m}^{-3}\right.$ $\left.\mathrm{ha}^{-1}\right)$. The fusel oil applied by sprayed on the sugarcane did not eradicated the ratoons, but the application directly on the soil eradicated the ratoons and did not damage the sunflower plants development sowed in succession.

Key words: Saccharum spp., Helianthus annuus, agroindustrial residue, ratoons.

(1) Recebido para publicação em 9 de junho de 2008 e aceito em 26 de janeiro de 2010.

() Centro de Cana, Instituto Agronômico, Caixa Postal 206, 14001-970 Ribeirão Preto (SP). E-mail azania@iac.sp.gov.br.

$\left({ }^{*}\right)$ Autor corrrespondente.

(3) Pesquisador Voluntário.

(4) Bolsista Fundag.

(5) Bolsista CNPq/Pibic.

$\left.{ }^{(}\right)$Mestrando em Tecnologia da Produção Agrícola, Instituto Agronômico. 


\section{INTRODUÇÃO}

O óleo fúsel é produto da transformação de aminoácidos pelas leveduras, durante a fermentação alcoólica em destilarias, e seus componentes são conhecidos como álcoois superiores (BоTELHO, 1945). Em sua composição podem ser encontrados álcoois etílico, amílico, isoamílico, propílico, butílico e outros. Segundo Almazan et al. (1998), os álcoois amílico, isoamílico, n-butanol e outros compostos do óleo fúsel podem ser separados através de processo de destilação, com algumas vantagens econômicas. Segundo NASCIMENTO et al. (2003), o álcool isoamílico é explorado pelas indústrias químicas como reagente, em sínteses orgânicas ou como solvente na extração de compostos farmacológicos, como os ésteres.

O óleo fúsel é o único subproduto da indústria sucroalcooleira não utilizado na agricultura e, por esse motivo, foram iniciados trabalhos envolvendo o uso do resíduo. Azania et al. (2004) observaram que este subproduto, em todas as concentrações testadas (100; 50; 25 e 12,5 v/v), inibiu a emergência de plântulas de Sida rhombifolia e Brachiaria decumbens, além de ter dessecado plantas de cana-de-açúcar. Segundo AzANIA et al. (2003), a redução na viabilidade de sementes de Sida rhombifolia ocorreu principalmente nas maiores concentrações em que o produto foi aplicado. Por outro lado, nas sementes de Brachiaria decumbens houve inviabilização completa em todas as concentrações. O óleo fúsel em associação com glifosato também possibilitou, além de redução da dose do herbicida, controle excelente sobre uma comunidade natural de plantas daninhas, com exceção de espécies dos gêneros Commelina e Cyperus (AzANIA et al., 2008).

Entretanto, o óleo fúsel aplicado via pulverização foliar isoladamente, não promoveu a dessecação completa da cana-de-açúcar, mas em associação com glifosato, dessecou o perfilho principal (AzANIA, 2007). Neste mesmo trabalho, o óleo fúsel aplicado antes do plantio, não causou interferência sobre a germinação e viabilidade das sementes de plantas daninhas, contudo em aplicação após o plantio, na pós-emergência das plantas infestantes, o produto proporcionou controle pouco satisfatório.

A reforma do canavial é necessária porque a partir da primeira colheita após o plantio a produção de colmos diminui naturalmente após a colheita de cada soqueira. Segundo Coleti (2008), o novo plantio inicia-se com a destruição da soqueira, realizada pela aplicação de herbicidas dessecantes e, após a erradicação completa, as plantas são destruídas mecanicamente.

$\mathrm{Na}$ reforma do canavial, o emprego do óleo fúsel poderia ser outra opção aos produtores, que consequentemente teriam benefícios econômicos e ambientais pela aplicação da menor quantidade de herbicidas dessecantes. Entretanto, a utilização do óleo fúsel precisa ser mais bem estudada, uma vez que o resíduo apenas evidencia seu potencial dessecante. $\mathrm{O}$ plantio de cana-de-açúcar, por ser oneroso e consumir quantidade considerável de herbicidas, que podem até mesmo prejudicar o ambiente, poderia ser beneficiado com o uso deste subproduto. Pérez et al. (2001) considera que o baixo valor comercial do óleo fúsel, associado ao alto volume de produção por safra, são fatores que devem estimular propostas de desenvolvimento de tecnologia para sua utilização.

Independentemente da escolha do herbicida dessecante, nas áreas de reforma de canavial, é essencial a seletividade à cana-de-açúcar e também às espécies que podem ser cultivadas em sucessão às soqueiras erradicadas. O cultivo de leguminosas (BolonHeZI, 2007) - girassol e amendoim (RAmos et al., 2009) - é comum ser realizado após a erradicação das soqueiras e antes do plantio do novo canavial; para PIRES et al. (2003), porém, é imprescindível que o solo não tenha resíduo de herbicidas não seletivos a essas culturas para garantir o desenvolvimento das plantas.

O girassol é cultivado para obtenção de massa verde a ser incorporada ao solo, objetivando melhorar as propriedades físico-químicas. No caso do óleo fúsel, é interessante identificar doses que permitam o desenvolvimento do girassol ou outras culturas após a erradicação das soqueiras.

Nessecontexto, paramelhorevidenciarautilização do óleo fúsel objetivou-se testar a hipótese de que o óleo fúsel aplicado via pulverização ou diretamente no solo promove a erradicação das soqueiras sem prejudicar o desenvolvimento do girassol em sucessão.

\section{MATERIAL E MÉTODOS}

O experimento foi realizado em Ribeirão Preto (SP), em plantas de cana-de-açúcar previamente plantadas em vasos plásticos de $22 \mathrm{~L}$ de capacidade preenchidos com terra oriunda da camada arável do solo e alocados em local aberto e sob sistema de irrigação.

A terra utilizada era composta de $24 \mathrm{~g} \mathrm{dm}^{-3}$ de matéria orgânica; 5,6 de $\mathrm{pH}\left(\mathrm{CaCl}_{2}\right) ; 38 \mathrm{mg} \mathrm{dm}^{-3}$ de $\mathrm{P}$; 3,4 $\mathrm{mmol}_{\mathrm{c}} \mathrm{dm}^{-3}$ de K; $54 \mathrm{mmol}_{\mathrm{c}} \mathrm{dm}^{-3}$ de Ca; $24 \mathrm{mmol}_{\mathrm{c}}$ $\mathrm{dm}^{-3}$ de Mg; CTC de 117,4 e V de 69,3\%. Segundo as recomendações de EsPIRONELO (1992), não foi necessária a adição de calcário para correção da acidez, mas sim a adubação com o equivalente a 20, 80 e $80 \mathrm{~kg} \mathrm{ha}^{-1}$ de $\mathrm{N}, \mathrm{P}_{2} \mathrm{O}_{5}$ e $\mathrm{K}_{2} \mathrm{O}$, respectivamente, uma semana antes do transplante das mudas. As plantas receberam ainda $20 \mathrm{~kg} \mathrm{ha}^{-1}$ de $\mathrm{N}$ como adubação de cobertura, quando estavam com altura média de $20 \mathrm{~cm}$. 
As mudas de cana-de-açúcar foram preparadas de acordo com a metodologia de AZANIA (2003) e quando atingiram altura entre 10 e $15 \mathrm{~cm}$, foram transplantadas para os vasos. Quando as plantas atingiram $39,5 \mathrm{~cm}$, foram cortadas rente ao solo, para simular a soqueira da cana-de-açúcar e receberam uma segunda adubação em cobertura, similar à primeira, aos 30 dias após o corte. Após esse procedimento, as plantas receberam irrigação suficiente para manter o desenvolvimento até o momento da aplicação dos tratamentos.

\section{Etapa 1 - Aplicação de óleo fúsel via foliar}

Foi utilizado o delineamento experimental inteiramente casualizado com 22 tratamentos e três repetições, em esquema fatorial $(7 \times 3)+1$; o primeiro fator foi constituído por concentrações de óleo fúsel ou glifosato, o segundo fator, constituído pelos volumes de calda e o tratamento adicional, pela testemunha, sem aplicação.

O óleo fúsel foi aplicado nas concentrações de $6,25 \%$ e $12,50 \%$ (baixa concentração), $25 \%$ e $50 \%$ (média concentração) e 75\% e 100\% (alta concentração) e o glifosato (2520 $\left.\mathrm{g} \mathrm{ha}^{-1}\right)$, utilizado como padrão de aplicação. Todos estes tratamentos foram aplicados com pulverizador costal pressurizado, regulado para proporcionar os três volumes de calda, a saber: 250, 350 e $450 \mathrm{~L} \mathrm{ha}^{-1}$. Por ocasião da aplicação, as plantas de canade-açúcar, com 85 dias após o corte, estavam com 38,13 $\mathrm{cm}$ de altura média.

Acana-de-açúcarfoiavaliadaquantoaossintomas visuais de fitointoxicação (aos 7, 14 e 28 DAA - dias após aplicação), altura ( $7,14,28$ e 60 DAA) e massa seca (60 DAA). As avaliações dos sintomas de fitointoxicação constaram da atribuição de notas percentuais variando de 0 a $100 \%$, sendo $0 \%$ correspondente à ausência de injúrias e $100 \%$ à morte das plantas. A altura foi obtida aferindo-se o comprimento $(\mathrm{cm})$ da superfície do solo até a lígula da primeira folha completamente desenvolvida, em três perfilhos tomados ao acaso em cada parcela.

\section{Etapa 2 - Aplicação de óleo fúsel via solo}

O delineamento foi inteiramente casualizado com 12 tratamentos e três repetições. Os tratamentos foram constituídos pela ausência de óleo fúsel (testemunha) e pela aplicação direta ao solo de 0,$1 ; 0,5 ; 1 ; 5 ; 10 ; 25 ; 50$; 75; 100; 125 e $150 \mathrm{~m}^{3} \mathrm{ha}^{-1}$ do resíduo.

A escolha dos tratamentos foi decorrente de resultados anteriores(AzANIA, 2003), osquaisconstataram que $150 \mathrm{~m}^{3} \mathrm{ha}^{-1}$ do subproduto foram suficientes para erradicar a cana-de-açúcar. As quantidades de óleo fúsel estabelecidas por tratamento $\left(\mathrm{m}^{3} \mathrm{ha}^{-1}\right)$ foram calculadas para um volume de $22 \mathrm{~L}$, capacidade dos vasos (parcelas).

A aplicação dos tratamentos foi feita diretamente no solo dos vasos, sendo o preparo da calda e sua caracterização quanto ao $\mathrm{pH}$ e à condutividade elétrica realizado no mesmo dia. Por ocasião da aplicação, as plantas também estavam com 85 dias após corte e altura média de 38,13 cm.

A eficiência do óleo fúsel foi avaliada aferindo-se os sintomas de intoxicação aos 7 DAA, altura das plantas (solo ao "dew-lap") aos 7, 15, 28 e 45 DAA e massa seca das plantas aos 60 DAA. As avaliações dos sintomas de intoxicação foram realizadas visualmente utilizandose notas percentuais que variaram de $0 \%$ (ausência de injúrias) a 100\% (morte das plantas).

\section{Etapa 3 - Efeito residual de óleo fúsel sobre o girassol em sucessão}

O delineamento experimental foi inteiramente casualizado com oito tratamentos e três repetições. Os tratamentos foram constituídos pela semeadura de girassol sobre as plantas de cana-de-açúcar erradicadas pela aplicação de $5,10,25,50,75,100,125$ e $150 \mathrm{~m}^{3} \mathrm{ha}^{-1}$ de óleo fúsel via solo.

A semeadura do girassol cultivar Iarama IAC foi feita em número de 10 sementes / parcela, aos 66 dias após a aplicação de óleo fúsel no solo, ocasião que as plantas completavam 210 dias após transplante das mudas.

A germinação das sementes de girassol foi acompanhada diariamente durante 11 dias, aferindo-se o número de plântulas emergidas, para posterior cálculo do Índice de Velocidade de Emergência e Velocidade de Emergência (MAGUiRE, 1962).

O percentual de germinação também foi calculado utilizando-se da equação $\chi=100 * n_{1} / n_{2^{\prime}}$ sendo $n_{1}=$ número de plântulas final e $n_{2}=$ número de sementes semeadas, a partir do número de plântulas contadas aos 11 dias após semeadura (DAS). Nessa ocasião realizouse o desbaste, deixando-se uma única planta de girassol em cada parcela.

A altura e o número de folhas foram aferidos aos 18, 32, 49 e 64 DAS. A altura foi obtida medindose o comprimento das plantas do solo até ao ápice e o número de folhas anotado pela contagem direta. A massa seca foi obtida aos 60 DAS, coletando-se todas as plantas com posterior secagem em estufa de circulação forçada a ar, em temperatura constante de $70{ }^{\circ} \mathrm{C}$ até massa constante.

Os valores de $\mathrm{pH}\left(\mathrm{CaCl}_{2}\right)$, M.O. $\left(\mathrm{g} \mathrm{dm}^{-3}\right), \mathrm{V}(\%)$, CTC e $\mathrm{K}, \mathrm{Mg}, \mathrm{Ca}, \mathrm{Al}, \mathrm{H}+\mathrm{A}\left(\mathrm{mmol}_{\mathrm{c}} \mathrm{dm}^{-3}\right)$ do solo foram determinados aos 150 DAT, em cada parcela, a partir de amostra de solo na profundidade de $0-20 \mathrm{~cm}$. 


\section{RESULTADOS E DISCUSSÃO}

\section{Etapa 1 - Aplicação de óleo fúsel via foliar}

Os sintomas de intoxicação puderam ser observados até aos 28 DAA, especialmente nos tratamentos com glifosato, que causaram sempre as maiores injúrias na parte aérea das plantas. O glifosato causou injúrias da ordem de 78,33\% da parte aérea das folhas aos7 DAAe $93,33 \%$ aos 28DAA, quando as plantas estavam praticamente erradicadas. Considerando a eficiência dos produtos utilizados quanto à erradicação, o glifosato se destacou em todas as avaliações, diferindo do óleo fúsel em todas as concentrações utilizadas (Tabela 1). Esses resultados foram similares aos observados por AzANIA (2007), que obteve a erradicação completa da cultura aos 60 DAA, possivelmente devido à aplicação do glifosato (1440 $\left.\mathrm{g} \mathrm{ha}^{-1}\right)$.

A eficácia do glifosato era esperada, pois é o herbicida mais utilizado na erradicação da canade-açúcar. Segundo LORENZI (1983), as doses para erradicação podem variar entre 1440 a $3360 \mathrm{~g} \mathrm{ha}^{-1}$, dependendo da suscetibilidade do cultivar. Mais recentemente, Silva et al. (2006) também obtiveram erradicação de quatro genótipos de cana-de-açúcar utilizando a dose de $2400 \mathrm{~g} \mathrm{ha}^{-1}$.
O uso do óleo fúsel também causou injúrias severas nas folhas da cana-de-açúcar, especialmente nas concentrações de $75 \%$ e $100 \%$, até aos 14 DAA, nas quais foram observados, aos 7 e 14 DAA, respectivamente, $35 \%$ e $50 \%$ e $28,33 \%$ e $37,50 \%$ de intoxicação na parte aérea das plantas. Entretanto, aos 28 DAA em todos os tratamentos com óleo fúsel foram observados sintomas de intoxicação entre 23,33\% a 30,83\% , não diferindo entre si (Tabela 1). A tendência de o resíduo causar sintomas de intoxicação elevados logo após a aplicação, seguida da recuperação das plantas, também foi observada por AzAnia (2007), que constatou 55\% de injúrias aos 21 DAA e $20 \%$ aos 60 DAA.

Em relação aos volumes de calda utilizados, não se observou influência na manifestação dos sintomas de intoxicação, em todas as épocas avaliadas (Tabela 1).

Em todas as avaliações, exceto aos 7 DAA, as aplicações dos produtos interferiram sobre a altura das plantas (Tabela 2), e no tratamento com glifosato aos 60 DAA não foi mais possível aferir esta característica. Observou-se que o glifosato, desde os 14 DAA, interferiu sobre a altura das plantas de cana-de-açúcar, paralisando o crescimento de forma gradativa até aos 60 DAA, ocasião em que a planta estava totalmente erradicada. SiLva e Rosseto (2002) também conseguiram

Tabela 1. Sintomas de fitointoxicação na cana-de-açúcar cultivar IACSP 93-3046, tratada com glifosato e com diferentes concentrações de óleo fúsel. Ribeirão Preto (SP)

\begin{tabular}{|c|c|c|c|c|c|c|}
\hline \multirow{3}{*}{ Tratamentos } & \multicolumn{6}{|c|}{ Sintomas de fitointoxicação } \\
\hline & \multicolumn{2}{|c|}{$7 \mathrm{DAA}$} & \multicolumn{2}{|c|}{$14 \mathrm{DAA}$} & \multicolumn{2}{|c|}{$28 \mathrm{DAA}$} \\
\hline & Orig. & Transf. & Orig. & Transf. & Orig & Transf. \\
\hline & & & & & & \\
\hline Óleo fúsel 6,25\% & 0 & $4,05 e$ & 12,5 & $20,91 d$ & 23,33 & $28,95 b$ \\
\hline Óleo fúsel $12 \%$ & 0 & $4,05 e$ & 13,33 & $21,58 d$ & 24,16 & $29,50 b$ \\
\hline Óleo fúsel $25 \%$ & 0,83 & $5,29 e$ & 12,5 & $20,91 d$ & 26,67 & $31,27 b$ \\
\hline Óleo fúsel $50 \%$ & 8,3 & $14,44 d$ & 19,16 & $26,25 c d$ & 25,83 & $30,53 b$ \\
\hline Óleo fúsel $75 \%$ & 35,0 & $36,48 c$ & 28,33 & $32,37 b c$ & 26,67 & $31,22 b$ \\
\hline Óleo fúsel 100 \% & 50,0 & $45,29 b$ & 37,50 & $38,00 \mathrm{~b}$ & 30,83 & $33,85 b$ \\
\hline glifosato & 78,33 & $62,68 a$ & 86,66 & $71,04 a$ & 93,33 & $78,84 a$ \\
\hline Testemunha & 0 & 4,05 & 0 & 4,05 & 0 & 4,05 \\
\hline $250 \mathrm{~L} \mathrm{ha}^{-1}$ & & 22,98 & & 31,42 & & 38,24 \\
\hline $350 \mathrm{~L} \mathrm{ha}^{-1}$ & & 24,69 & & 33,16 & & 36,76 \\
\hline $450 \mathrm{~L} \mathrm{ha}^{-1}$ & & 26,17 & & 34,45 & & 38,22 \\
\hline $\mathrm{F}$ produtos $(\mathrm{A})$ & & $235,3 * *$ & & $154,4 * *$ & & $96,6^{* *}$ \\
\hline F vol. calda (B) & & 2,52 & & 2,59 & & 0,49 \\
\hline $\mathrm{F}_{\mathrm{AxB}}$ & & 0,99 & & 0,53 & & 0,87 \\
\hline $\mathrm{F}_{\text {Test. } \mathrm{x} \text { fatorial }}$ & & $56,85^{* *}$ & & $127,39 * *$ & & $105,4 * *$ \\
\hline dms produtos & & 6,61 & & 6,22 & & 7,95 \\
\hline dms volumes & & 3,42 & & 3,22 & & 4,11 \\
\hline $\mathrm{CV}(\%)$ & & 22,50 & & 15,82 & & 17,70 \\
\hline
\end{tabular}

DAA: dias após aplicação. Orig.: dados originais. Transf.: dados transformados em arc sen raiz x+0,5, nas colunas, médias seguidas de letras diferentes, diferem entre si (Tukey, 5\%). 
Tabela 2. Altura e massa seca das plantas de cana-de-açúcar cultivar IACSP 93-3046, tratadas com glifosato e diferentes concentrações de óleo fúsel. Ribeirão Preto (SP)

\begin{tabular}{|c|c|c|c|c|c|}
\hline \multirow{2}{*}{ Tratamentos } & \multicolumn{4}{|c|}{ Altura } & \multirow{2}{*}{$\begin{array}{c}\text { Massa seca } \\
60 \text { DAA }\end{array}$} \\
\hline & 7 DAA & 14 DAA & $28 \mathrm{DAA}$ & $60 \mathrm{DAA}$ & \\
\hline & &  & & 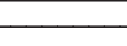 & $\mathrm{g}$ \\
\hline Óleo fúsel 6,25\% & 30,11 & $37,58 a$ & $46,70 a$ & $59,81 a$ & $207,68 a$ \\
\hline Óleo fúsel 12\% & 28,83 & $33,61 a b$ & $45,31 a$ & $60,09 a$ & $192,18 a$ \\
\hline Óleo fúsel $25 \%$ & 31,70 & $37,61 a$ & $48,97 a$ & $62,03 a$ & $215,65 a$ \\
\hline Óleo fúsel $50 \%$ & 31,61 & $38,81 a$ & $46,08 a$ & $57,36 a$ & $234,68 a$ \\
\hline Óleo fúsel 75\% & 30,31 & $34,42 a b$ & $45,25 a$ & $58,17 a$ & $193,05 a$ \\
\hline Óleo fúsel 100\% & 29,61 & $32,33 a b$ & $46,83 a$ & $64,33 a$ & $207,87 a$ \\
\hline glifosato & 27,97 & $26,67 b$ & $30,22 b$ & $0,00 b$ & $62,79 b$ \\
\hline Testemunha & 34,25 & 48,08 & 53,08 & 85,54 & 476,03 \\
\hline $250 \mathrm{~L} \mathrm{ha}^{-1}$ & 30,48 & 35,70 & 43,50 & 52,81 & 191,53 \\
\hline $350 \mathrm{~L} \mathrm{ha}^{-1}$ & 30,64 & 33,54 & 43,86 & 48,71 & 178,12 \\
\hline $450 \mathrm{~L} \mathrm{ha}^{-1}$ & 28,94 & 34,06 & 45,23 & 53,52 & 193,44 \\
\hline $\mathrm{F}$ produtos $(\mathrm{A})$ & 0,79 & $4,94 * *$ & $11,35^{* *}$ & $69,65^{* *}$ & $7,72 * *$ \\
\hline F vol. calda (B) & 0,87 & 0,85 & 0,56 & 2,09 & 0,39 \\
\hline $\mathrm{F}_{\mathrm{AxB}}$ & 1,08 & 1,26 & 0,65 & 0,15 & 0,27 \\
\hline $\mathrm{F}_{\text {Test. } \mathrm{x} \text { fatorial }}$ & 2,39 & $16,82 * *$ & $7,21^{* *}$ & $48,40 * *$ & $62,98 * *$ \\
\hline dms produtos & 6,62 & 8,07 & 8,02 & 11,80 & 88,07 \\
\hline dms volumes & 3,42 & 4,17 & 4,15 & 6,10 & 45,52 \\
\hline $\mathrm{CV}(\%)$ & 17,67 & 18,55 & 14,50 & 17,87 & 35,35 \\
\hline
\end{tabular}

DAA:dias após aplicação; nas colunas, médias seguidas de letras diferentes, diferem entre si (Tukey, 5\%).

a erradicação da cultura após 45 DAA, possivelmente devido à suscetibilidade das cultivares testadas.

Os tratamentos com óleo fúsel interferiram com menor intensidade na altura das plantas, mas em todas as avaliações os valores observados sempre foram menores que o das plantas do tratamento testemunha. Desde os 7 DAA o produto interferiu na altura das plantas de cana-deaçúcar em menor intensidade, pois as plantas continuaram a crescer, porém, sempre com valores menores que a testemunha. A partir dos $28 \mathrm{DAA}$, em todas as plantas tratadas com óleo fúsel a altura foi significativamente maior que as tratadas com glifosato (Tabela 2).

Os valores obtidos de massa seca das plantas de cana-de-açúcar também evidenciaram a eficiência do glifosato, que paralisou o crescimento das plantas, que estavam com menores acúmulos de massa seca. Entretanto, as diferentes concentrações do óleo fúsel apenas retardaram o crescimento das plantas, nas quais havia maior acúmulo de massa seca que com glifosato e menores que na testemunha (Tabela 2). AzANIA (2007) não obteve a erradicação da cana-de-açúcar quando pulverizou óleo fúsel sobre a cana-de-açúcar, mas o acúmulo de massa seca foi similar ao tratamento com glifosato (1440 $\left.\mathrm{g} \mathrm{ha}^{-1}\right)$. Esta diferença de resultados pode estar relacionada às características varietais, comentadas por Ferreira (1986), SiLVA e Rossetto (2002).

\section{Etapa 2 - Aplicação de óleo fúsel via solo}

Aos 7 dias após o tratamento (DAT), a avaliação visual de sintomas de fitotoxicidade, detectou que os tratamentos a partir de $10 \mathrm{~m}^{3} \mathrm{ha}^{-1}$ foram suficientes para erradicar as plantas de cana-de-açúcar, provocando erradicação completa das plantas.

Aaltura das plantas foi influenciada pela aplicação dos produtos. Em todas as épocas avaliadas, o óleo fúsel aplicado nas doses de 0,1; 0,5 e $1 \mathrm{~m}^{3} \mathrm{ha}^{-1}$ diferiu dos demais tratamentos, e, juntamente com a testemunha, proporcionou os maiores valores de altura da canade-açúcar. A partir de $5 \mathrm{~m}^{3} \mathrm{ha}^{-1}$, a altura das plantas foi influenciada pela aplicação do óleo fúsel (Tabela 3). Para LoRENZI (1983), o estádio de desenvolvimento constitui fator importante na dessecação das plantas, pois estas devem estar entre 40 e $80 \mathrm{~cm}$ de altura. De acordo com SANTOS et al. (1984), a época mais adequada para erradicação de variedades de cana-de-açúcar é 65 dias após o corte. Já para SILVA et al. (2006), a melhor época de aplicação de dessecante para a erradicação de soqueira de cana-de-açúcar foi de 40 dias após o terceiro corte. Verifica-se que a influência varietal neste tipo de trabalho é muito importante, pois variedades de canade-açúcar possuem diferentes graus de suscetibilidade para completa destruição de soqueiras por meio de uso do glifosato (LorenzI, 1983). No presente trabalho, 
utilizando óleo fúsel, foram observados resultados satisfatórios de dessecação já aos sete dias após a aplicação do produto ao solo, trabalhando-se com soqueiras de 44 dias após corte.

Quanto à massa seca das plantas de canade-açúcar, os maiores valores foram constados na testemunha e nas menores concentrações do óleo fúsel, como pode ser visualizado na tabela 4 . Esses resultados são similares aos obtidos por AzANIA (2007).

A testemunha diferiu de todos os tratamentos com óleo fúsel, exceto nas doses de 0,5 e $1 \mathrm{~m}^{3} \mathrm{ha}^{-1}$ de óleo fúsel. É importante observar que a massa seca obtida com a dose de $5 \mathrm{~m}^{3}$ ha-1 não diferiu significativamente da obtida na aplicação da dose de $150 \mathrm{~m}^{3} \mathrm{ha}^{-1}$ (Tabela 4).

Tabela 3. Altura das plantas de cana-de-açúcar ao longo do tempo, cultivar IACSP 93-3046, tratadas diferentes concentrações de óleo fúsel. Ribeirão Preto (SP)

\begin{tabular}{|c|c|c|c|c|c|c|c|c|}
\hline \multirow{3}{*}{ Óleo fúsel } & \multicolumn{8}{|c|}{ Altura das plantas } \\
\hline & \multicolumn{2}{|c|}{7 DAT } & \multicolumn{2}{|c|}{ 15 DAT } & \multicolumn{2}{|c|}{28 DAT } & \multicolumn{2}{|c|}{45 DAT } \\
\hline & Orig. & Transf. & Orig. & Transf. & Orig. & Transf. & Orig. & Transf. \\
\hline \multicolumn{9}{|l|}{$\mathrm{m}^{3} \mathrm{ha}^{-1}$} \\
\hline 0 & 35,33 & $6,02 a$ & 42,33 & $6,57 a$ & 36,33 & $6,11 a$ & 33,67 & $3,99 a$ \\
\hline 0,1 & 34,67 & $5,97 a$ & 41,33 & $6,50 a$ & 39,11 & $6,35 a$ & 33,78 & $4,19 a$ \\
\hline 0,5 & 31,33 & $5,68 a$ & 36,00 & $6,06 a$ & 38,78 & $6,30 a$ & 39,00 & $4,41 a$ \\
\hline 1 & 32,67 & $5,80 a$ & 35,00 & $6,00 a$ & 36,33 & $6,10 a$ & 39,44 & $4,07 a$ \\
\hline 5 & 11,33 & $2,64 b$ & 11,33 & $2,64 b$ & 11,56 & $2,67 b$ & 14,44 & $2,12 b$ \\
\hline 10 & 0 & $1,00 \mathrm{~b}$ & 0 & $1,00 b$ & 0 & $1,00 b$ & 0 & $1,00 \mathrm{~b}$ \\
\hline 25 & 0 & $1,00 \mathrm{~b}$ & 0 & $1,00 b$ & 0 & $1,00 b$ & 0 & $1,00 \mathrm{~b}$ \\
\hline 50 & 0 & $1,00 \mathrm{~b}$ & 0 & $1,00 \mathrm{~b}$ & 0 & $1,00 b$ & 0 & $1,00 \mathrm{~b}$ \\
\hline 75 & 0 & $1,00 \mathrm{~b}$ & 0 & $1,00 \mathrm{~b}$ & 0 & $1,00 \mathrm{~b}$ & 0 & $1,00 \mathrm{~b}$ \\
\hline 100 & 0 & $1,00 \mathrm{~b}$ & 0 & $1,00 \mathrm{~b}$ & 0 & $1,00 \mathrm{~b}$ & 0 & $1,00 b$ \\
\hline 125 & 0 & $1,00 \mathrm{~b}$ & 0 & $1,00 b$ & 0 & $1,00 \mathrm{~b}$ & 0 & $1,00 \mathrm{~b}$ \\
\hline 150 & 0 & $1,00 \mathrm{~b}$ & 0 & $1,00 b$ & 0 & $1,00 \mathrm{~b}$ & 0 & $1,00 \mathrm{~b}$ \\
\hline $\mathrm{F}$ & & $23,77 * *$ & & $27,02 * *$ & & $25,52 * *$ & & $18,29 * *$ \\
\hline $\operatorname{dms}(5 \%)$ & & 2,45 & & 2,50 & & 2,54 & & 1,82 \\
\hline $\mathrm{CV}(\%)$ & & 30,18 & & 29,30 & & 29,92 & & 28,75 \\
\hline
\end{tabular}

DAT: dias após tratamento, Orig.: dados originais. Transf.: dados transformados em raix $\mathrm{x}+1$, nas colunas, médias seguidas da mesma letra, não diferem entre si (Tukey, 5\%).

Tabela 4. Biomassa seca da parte aérea das plantas de cana-de-açúcar cultivar IACSP 93-3046, determinada aos 45 dias após a aplicação das diferentes concentrações de óleo fúsel. Ribeirão Preto (SP)

\begin{tabular}{|c|c|}
\hline Óleo fúsel & Biomassa seca da parte aérea aos 45 DAT \\
\hline $\mathrm{m}^{3} \mathrm{ha}^{-1}$ & $\mathrm{~g}$ \\
\hline 0 & $363,12 a$ \\
\hline 0,1 & $194,83 b c d$ \\
\hline 0,5 & $216,22 a b c$ \\
\hline 1 & $245,07 a b$ \\
\hline 5 & $105,60 \mathrm{bcde}$ \\
\hline 10 & $16,44 e$ \\
\hline 25 & $36,25 e$ \\
\hline 50 & $36,56 e$ \\
\hline 75 & $50,28 d e$ \\
\hline 100 & 60,43 cde \\
\hline 125 & $76,27 c d e$ \\
\hline 150 & $60,76 c d e$ \\
\hline $\mathrm{F}$ & $12,23 * *$ \\
\hline dms $(5 \%)$ & 157,49 \\
\hline $\mathrm{CV}(\%)$ & 43,91 \\
\hline
\end{tabular}

DAT: dias após tratamento; nas colunas, médias seguidas da mesma letra, não diferem entre si (Tukey, 5\%). 
A esta altura, deve ser mencionado que a caracterização dos atributos químicos do solo após aplicação do produto torna-se muito importante, por se tratar de aplicações diretas no solo. Na tabela 5 pode-se observar os dados referentes aos principais atributos químicos do solo, determinados aos $150 \mathrm{DAT}$, em função dos tratamentos. O óleo fúsel aplicado em quantidades de até $150 \mathrm{~m}^{3} \mathrm{ha}^{-1}$ não alterou os atributos químicos do solo essenciais ao desenvolvimento das plantas, exceto os valores de fósforo que, a partir de $0,1 \mathrm{~m}^{3} \mathrm{ha}^{-1}$ de óleo fúsel, foram inferiores àqueles da testemunha.

Esse resultado não foi observado por AzANIA (2003), que obteve, porém, menores valores de $\mathrm{pH}$ e maiores de alumínio, não detectados no presente trabalho. Essas diferenças podem estar associadas à composição física dos solos estudados, especialmente aos teores de argila.

A não-alteração da maioria dos atributos químicos do solo pelo óleo fúsel, observada nos trabalhos de AZANIA $(2003 ; 2007)$ e corroborada pelos resultados desta pesquisa, sinaliza positivamente para a continuidade deste tipo de estudo. Não se deve esquecer que resíduos agroindustriais, como o óleo fúsel, geralmente são desbalanceados quimicamente, devendo ser aplicados no ambiente com cautela.

\section{Etapa 3 - Efeito residual de óleo fúsel sobre o girassol em sucessão}

Oestabelecimento inicial (Tabela6) e o crescimento do girassol (Tabela 7) tiveram diferenças significativas. O desenvolvimento final do girassol, aferido pela massa seca de diferentes partes das plantas aos 64 dias após semeadura(DAS), em pleno florescimento, éapresentado na tabela 8. Do mesmo modo, não foram verificadas diferenças significativas entre os tratamentos.

Com base nos resultados (Tabelas 6, 7 e 8), podese afirmar que o desenvolvimento do girassol cultivado em sucessão à cana-de-açúcar não foi influenciado pelas concentrações de óleo fúsel aplicadas.

Talvez não tenha havido comprometimento da cultura devido à baixa persistência dos resíduos no solo. Sabe-se que pode ocorrer a degradação de substâncias no solo pela ação de microrganismos, pela luz e temperatura ambiente, dentre outros fatores. Pelos dados obtidos por Azania (2007), a atividade microbiana no solo foi similar nos diferentes tratamentos com óleo fúsel e considerada um dos principais fatores responsáveis pela rápida degradação dos diferentes álcoois componentes daquele resíduo.

Pelos resultados, confirmou-se que o desenvolvimento do girassol cultivado em sucessão à

Tabela 5. Atributos químicos do solo após erradicação da cana-de-açúcar cultivar IACSP 93-3046, aos 150 dias após a aplicação das diferentes concentrações de óleo fúsel e posterior cultivo de girassol. Ribeirão Preto (SP)

\begin{tabular}{|c|c|c|c|c|c|c|c|c|c|c|}
\hline \multirow{2}{*}{$\begin{array}{l}\text { Óleo } \\
\text { fúsel }\end{array}$} & \multirow{2}{*}{ M.O. } & \multirow{2}{*}{$\mathrm{pH}$} & \multirow{2}{*}{$\mathrm{P}$ (resina) } & \multicolumn{6}{|c|}{ Cátions } & \multirow{2}{*}{$\mathrm{V}$} \\
\hline & & & & $\mathrm{K}^{+}$ & $\mathrm{Ca}^{2+}$ & $\mathrm{Mg}^{2+}$ & $\mathrm{H}+\mathrm{Al}$ & SB & CTC & \\
\hline $\mathrm{m}^{3} \mathrm{ha}^{-1}$ & $\mathrm{~g} \mathrm{dm}^{-3}$ & $\mathrm{CaCl}_{2}$ & $\mathrm{mg} \mathrm{dm}{ }^{-3}$ & \multicolumn{6}{|c|}{$-\mathrm{mmol}_{\mathrm{c}} \mathrm{dm}^{-3}$} & $\%$ \\
\hline 0 & 38,00 & 5,03 & $68,00 a$ & $2,50 a b$ & 64,67 & 20,00 & 56,67 & 74,50 & 143,83 & 60,10 \\
\hline 0,1 & 38,67 & 5,20 & $43,00 b$ & $1,63 b$ & 56,50 & 22,33 & 47,67 & 77,57 & 145,30 & 65,90 \\
\hline 0,5 & 27,33 & 5,20 & $38,67 b$ & $1,83 a b$ & 60,00 & 21,00 & 48,00 & 82,33 & 130,83 & 63,30 \\
\hline 1 & 31,33 & 5,00 & $44,33 a b$ & $1,63 b$ & 54,00 & 17,67 & 56,00 & 73,30 & 129,30 & 56,40 \\
\hline 5 & 32,67 & 5,17 & $48,00 a b$ & $2,07 a b$ & 60,00 & 21,33 & 48,33 & 83,40 & 131,73 & 63,23 \\
\hline 10 & 34,67 & 5,17 & $46,67 a b$ & $3,13 a b$ & 66,33 & 22,67 & 50,00 & 83,30 & 142,13 & 64,53 \\
\hline 25 & 35,67 & 5,30 & $38,00 \mathrm{~b}$ & $2,77 a b$ & 67,33 & 23,67 & 46,67 & 82,47 & 140,43 & 66,37 \\
\hline 50 & 27,00 & 5,30 & $42,00 a b$ & $3,37 a$ & 55,33 & 20,67 & 46,00 & 79,37 & 125,37 & 63,23 \\
\hline 75 & 27,67 & 5,27 & $37,33 b$ & $2,97 a b$ & 60,67 & 21,67 & 46,33 & 85,30 & 131,63 & 64,80 \\
\hline 100 & 27,67 & 5,00 & $35,00 \mathrm{~b}$ & $2,10 a b$ & 54,00 & 19,33 & 54,00 & 75,43 & 129,43 & 58,20 \\
\hline 125 & 27,00 & 5,03 & $41,00 a b$ & $3,13 a b$ & 55,33 & 19,33 & 53,00 & 77,80 & 130,80 & 59,57 \\
\hline 150 & 32,33 & 4,97 & $36,00 b$ & $2,47 a b$ & 58,33 & 19,33 & 59,67 & 67,60 & 139,80 & 56,67 \\
\hline $\mathrm{F}$ & 0,88 & 1,37 & $2,62 *$ & $3,93 * *$ & 0,67 & 0,58 & 1,89 & 1,77 & 0,70 & 0,99 \\
\hline $\mathrm{dms}$ & 23,80 & 0,54 & 29,66 & 1,57 & 29,30 & 11,38 & 17,29 & 20,07 & 41,18 & 18,07 \\
\hline $\mathrm{CV}(\%)$ & 25,52 & 3,55 & 22,98 & 21,68 & 16,76 & 18,63 & 11,51 & 8,68 & 10,36 & 9,92 \\
\hline
\end{tabular}

Nas colunas, médias seguidas da mesma letra não diferem significativamente (Tukey 5\%). 
Tabela 6. Porcentagem de germinação, índice de velocidade de emergência e velocidade de emergência das plântulas de girassol, cultivar Iarama, cultivadas em sucessão à cana-de-açúcar, cultivar IACSP 93-3046 erradicada com óleo fúsel. Ribeirão Preto (SP)

\begin{tabular}{lcccc}
\hline \multirow{2}{*}{ Óleo fúsel } & Plântulas & Emergidas & IVE (11DAS) & OE (11 DAS) \\
\cline { 2 - 5 } & Orig. & Transf. & Orig. & Orig. \\
\hline $\mathrm{m}^{3} \mathrm{ha}^{-1}$ & 70 & 57,00 & 4,52 & 8,57 \\
5 & 73 & 60,00 & 4,23 & 8,57 \\
10 & 60 & 50,85 & 3,42 & 8,62 \\
25 & 80 & 63,93 & 4,87 & 8,50 \\
50 & 73 & 59,71 & 4,46 & 8,62 \\
75 & 70 & 57,79 & 4,06 & 8,70 \\
100 & 80 & 63,93 & 4,96 & 8,60 \\
125 & 83 & 66,15 & 4,42 & 8,80 \\
150 & & 0,83 & 0,65 & 0,66 \\
F & & 26,15 & 2,95 & 0,54 \\
dms & & 15,43 & 23,90 & 2,23 \\
CV $(\%)$ & & & \\
\hline
\end{tabular}

IVE: Índice de velocidade de emergência. VE: Velocidade de emergência. DAS: dias após semeadura. Orig.: dados originais. Transf.: dados transformados em raiz $x+0,5$.

Tabela 7. Altura de plantas e número de folhas de plantas de girassol, cultivar Iarama, cultivado em sucessão à cana-de-açúcar cultivar IACSP 93-3046, erradicada com diferentes concentrações de óleo fúsel. Ribeirão Preto (SP)

\begin{tabular}{|c|c|c|c|c|c|c|c|c|}
\hline \multirow{2}{*}{ Óleo fúsel } & \multicolumn{4}{|c|}{ Altura (DAS) } & \multicolumn{4}{|c|}{ Folhas (DAS) } \\
\hline & 18 & 32 & 49 & 64 & 18 & 32 & 49 & 64 \\
\hline $\mathrm{m}^{3} \mathrm{ha}^{-1}$ & \multicolumn{4}{|c|}{$-\mathrm{cm}$} & \multicolumn{4}{|c|}{$-\mathrm{N} .{ }^{\circ}$} \\
\hline 5 & 3,40 & 5,43 & 8,29 & 10,83 & 2,92 & 3,24 & 4,22 & 4,34 \\
\hline 10 & 3,39 & 5,72 & 9,42 & 12,29 & 2,92 & 3,21 & 4,64 & 4,63 \\
\hline 25 & 3,44 & 5,72 & 8,95 & 10,78 & 2,92 & 3,53 & 4,25 & 4,21 \\
\hline 50 & 3,66 & 6,12 & 10,2 & 11,88 & 3,02 & 3,63 & 4,71 & 4,71 \\
\hline 75 & 3,29 & 5,78 & 8,69 & 9,10 & 3,08 & 3,39 & 4,15 & 3,80 \\
\hline 100 & 3,74 & 6,14 & 9,92 & 11,57 & 2,79 & 3,63 & 3,89 & 3,86 \\
\hline 125 & 3,88 & 6,62 & 10,84 & 11,93 & 2,92 & 3,80 & 4,52 & 4,36 \\
\hline 150 & 3,80 & 6,37 & 10,55 & 11,54 & 2,92 & 3,80 & 4,38 & 4,26 \\
\hline $\mathrm{F}$ & 1,88 & 2,62 & 2,90 & 2,06 & 1,63 & 2,09 & 1,04 & 1,64 \\
\hline dms & 0,81 & 1,19 & 2,65 & 3,45 & 0,33 & 0,78 & 1,31 & 1,24 \\
\hline CV $(\%)$ & 7,97 & 7,02 & 9,73 & 10,86 & 3,93 & 7,86 & 10,59 & 10,22 \\
\hline
\end{tabular}

DAS: dias após semeadura.

Tabela 8. Biomassa seca obtida aos 64 dias após semeadura das plantas de girassol, cultivar Iarama, cultivado em sucessão à canade-açúcar cultivar IACSP 93-3046, erradicada com diferentes concentrações de óleo fúsel. Ribeirão Preto (SP)

\begin{tabular}{lccc}
\hline \multirow{2}{*}{ Óleo fúsel } & \multicolumn{3}{c}{ Massa seca } \\
\cline { 2 - 4 } & folhas & caule & flor \\
\hline $\mathrm{m}^{3} \mathrm{ha}^{-1}$ & & $\mathrm{~g}$ & 3,71 \\
5 & 4,17 & 5,24 & 4,63 \\
10 & 5,55 & 7,22 & 3,89 \\
25 & 4,31 & 4,98 & 5,19 \\
50 & 5,43 & 7,02 & 2,87 \\
75 & 3,71 & 4,31 & 3,77 \\
100 & 4,35 & 5,46 & 4,61 \\
125 & 4,86 & 6,58 & 4,86 \\
150 & 4,65 & 6,29 & 0,95 \\
F & 0,49 & 0,58 & 3,83 \\
dms & 4,42 & 6,68 & 32,30 \\
CV $(\%)$ & 33,72 & 40,11 & \\
\hline
\end{tabular}


cana-de-açúcar, erradicada por diferentes concentrações de óleo fúsel, foi satisfatório, quando semeado após 150 dias da aplicação do produto diretamente no solo.

\section{CONCLUSÃO}

O óleo fúsel aplicado via pulverização na canade-açúcar não erradicou as soqueiras, no entanto, a aplicação diretamente no solo foi eficiente na erradicação das soqueiras e não prejudicou o desenvolvimento das plantas de girassol em sucessão.

\section{AGRADECIMENTOS}

À Fapesp pelo apoio financeiro de auxílio à pesquisa e ao Técnico de Apoio Dorival Rodrigues pela dedicação durante a realização da pesquisa.

\section{REFERÊNCIAS}

ALMAZAN, O.; GONZALES, L.; GALVEZ, L. The sugarcane, its by-products and co-products. Réduit, Food and Agricultural Research Council, 1998. p.13-25.

AZANIA, A.A.P.M. Influência de subprodutos da indústria alcooleira nos atributos químicos do solo e em plantas de cana-de-açúcar, guanxuma e capim-braquiária. 2003. 81f. Dissertação (Mestrado em Produção Vegetal), - Faculdade de Ciências Agrárias e Veterinárias, Universidade Estadual Paulista, Jaboticabal.

AZANIA, A.A.P.M. Potencialidade herbicídica do óleo fúsel. 2007. 81f. Tese (Doutorado em Produção Vegetal) - Faculdade de Ciências Agrárias e Veterinárias, Universidade Estadual Paulista, Jaboticabal.

AZANIA, A.A.P.M.; AZANIA, C.A.M.; MARQUES, M.O.; PAVANI, M.C.M.D. Emergência e desenvolvimento de guanxuma (Sida rhombifolia), capim-braquiária (Brachiaria decumbens) e cana-de-açúcar (Sacharum spp.) influenciados por subprodutos da destilação do álcool. Planta Daninha, v.22, p.331-336, 2004.

AZANIA, A.A.P.M.; MARQUES, M.O.; PAVANI, M.C.M.D.; AZANIA, C.A.M. Germinação de sementes de Sida rhombifolia e Brachiaria decumbens influenciada por vinhaça, flegmaça e óleo de fúsel. Planta Daninha, v.21, p.443-449, 2003.

AZANIA, A.A.P.M; AZANIA, C.A.M.; MARQUES, M.O.; PAVANI, M.C.M.D.; FURTADO, D.E.; RODRIGUES, D. Aplicação de óleo fúsel isolado e em mistura com glifosato na pós-emergência tardia de plantas daninhas. Planta Daninha, v.26, p.231-236, 2008.

BOLONHEZI, D. Uso de adubos verdes na renovação de canavial. In: SEGATO, S. V. et al. (orgs.) Expansão e renovação de canavial. Piracicaba, 2007. cap.2, p.159-174.
BOTELHO, J. Impurezas do álcool etílico. Brasil açucareiro. Rio de Janeiro, v.25, p.99-101, 1945.

COLETI, J.T.O preparo de solo sob a ótica conservacionista. In: DINARDO-MIRANDA, L.L.; VASCONCELOS, A.C.M.; LANDELL, M.G.A. Cana-de-açúcar. 1.ed. Campinas: Instituto Agronômico, 2008. p.573-584.

ESPIRONELO, A. Cana-de-açúcar. In: RAIJ, B.van; SILVA, N.M.; BATAGLIA, O.C.;QUAGGIO, J.A.;HIROCE, R.;CANTARELLA, H.; BELLINAZZI JUNIOR, R.; DECHEN, A. R.; TRANI, P.E. Recomendações de adubação e calagem para o Estado de São Paulo. 2.ed. Campinas: Instituto Agronômico, 1992. p.10.

FERREIRA, M.O. A eficiência do glifosato na destruição química das socarias de cana-de-açúcar das variedades NA56-79 e CB45-3. STAB, Açúcar, Álcool e Subprodutos, v.4, p.46-48, 1986.

LORENZI, H. Plantas Daninhas e seu Controle na Cultura da Cana-de-Açúcar. In: REUNIÃO TÉCNICA AGRONÔMICA COPERSUCAR: PRAGAS DA CULTURA DA CANA-DEAÇÚCAR. Piracicaba: COPERSUCAR, 1983. p.59-73.

MAGUIRRE, J.B. Speed of germination-aid in selection and evaluation for seedling emergence and vigor. Crop Science, v.2, p.176-177, 1962.

NASCIMENTO, E.A.; MORAIS, S.L.; CASTRO, A.M. Análise dos constituintes do óleo fúsel. Disponível em: <http: / www. destilariaslenzi.com.br>. Acesso em: 2 mar. 2003.

PIRES, F.R.; SOUZA, C.M.; SILVA, A.A.; QUEIROZ, M.E.L.R.; PROCÓPIO, S.O.; SANTOS, J. B.; SANTOS, E.A.; CECON, P.R. Seleção de plantas com potencial para fitorremediação de tebuthiuron. Planta Daninha, v.21, p.451-458, 2003.

PÉREZ, E.R.; CARDOSO, D.R.; FRANCO, D.W. Análise dos álcoois, ésteres e compostos carbonílicos em amostras de óleo fúsel. Química Nova, v.24, p.10-12, 2001.

RAMOS, N.P.; NOVO, M.C.S.S.; LAGO, A.A.; UNGARO, M.R.G. Girassol: emergência e crescimento inicial de plantas sob resíduos de cana-de-açúcar. Ciência Rural, v.39, p.45-51, 2009.

SANTOS, A.J.R.; GRACIANO, S.P.; BACCHI, O.O.S.; KASHIWAKURA, Y. Doses e épocas de aplicação de glifosato na erradicação química de diferentes variedades de cana-deaçúcar. In: CONGRESSO NACIONAL DA SOCIEDADE DOS TÉCNICOS AÇUCAREIROS E ALCOOLEIROS DO BRASIL. 3., 1984, São Paulo. Anais... Piracicaba: STAB, 1984. p.276-281.

SILVA, M.A.; CARLIN, S.D.; CAPUTO, M.M. Tipos de colheita e épocas de aplicação de glifosato na erradicação de soqueiras de cana-de-açúcar. Pesquisa Agropecuária Brasileira, v.41, p.43-49, 2006.

SILVA, M.A.; ROSSETTO, R. Diferenças varietais na eliminação química de soqueiras de cana-de-açúcar. STAB, Açúcar, Álcool e Subprodutos, v.20, p.24-27, 2002. 